\title{
Praktische Hinweise
}

Dienstleistungen rund um das Thema Dokumentenmanagement werden von zwei auf dieses Thema spezialisierte Unternehmensberatungen angeboten:

- Project Consult

- Zöller\&Partner

Der Markt für Dokumentenmanagementsoftware im internationalen Rahmen wird dominiert von einigen wenigen Unternehmen:

- IBM/Filenet

- OpenText

- Alfresco

Der deutsche Markt wird von mittelständischen Unternehmen geprägt. Dazu zählen:

- SER

- ELO Office

- Docuware

- Enaio/Optimal Systems

Unabhängige Informationen/Leitfäden und Vergleiche der Produkte bieten drei Verbände/ Organisationen:

- Bitkom

- BARC

- VOI

Auch wenn das Thema Dokumentenmanagement selbst nicht im Fokus steht, ist ersichtlich, dass der Markt produktmäßig und informationstechnisch gut erschlossen ist. 